ARTICLE

https://doi.org/10.1057/s41599-019-0287-9

\title{
Using the Phylo Card Game to advance biodiversity conservation in an era of Pokémon
}

\author{
Megan M. Callahan ${ }^{1}$, Alejandra Echeverri ${ }^{1}$, David $\mathrm{Ng}^{2}$, Jiaying Zhao ${ }^{1,3}$ \& Terre Satterfield ${ }^{1}$
}

\begin{abstract}
Broader realization of both increasing biodiversity loss and pressures on ecosystems worldwide has highlighted the importance of public perceptions of species and the subsequent motivations towards improving the status of natural systems. Several new proposals have arisen in reference to environmental learning, including mimicking popular gaming media. Inspired by the popular game Pokémon, the Phylo Trading Card Game (Phylo game) is one such emerging possibility. It was invented as an open-source, competitive, and interactive game to inform players' knowledge of species, ecosystems, and negative environmental events (e.g., climate change, oil spills, wildfires). The game has now achieved global reach, yet the impact of this game on conservation behavior has never been tested. This study used a randomized control trial to evaluate the Phylo game's impact on conservation behavior (i.e., Phylo condition). This was compared to an information control condition with a more traditional learning method using a slideshow (i.e., Slideshow condition). A second card game was used to control for the act of playing a game (i.e., Projects condition). We found that ecological perceptions (i.e., the perceived relationship of species to their ecosystems) and species knowledge increased after both the game and the slideshow, but the Phylo Game had the added benefit of promoting more positive affect and more species name recall. It also motivated donation behavior in the direction of preventing negative environmental events instead of directly aiding an individual species or ecosystem. Our findings highlight the potential value of this game as a novel engagement tool for enhancing ecological literacy, motivations, and actions necessary to meet ecological challenges.
\end{abstract}

\footnotetext{
${ }^{1}$ Insitute for Resources, Environment and Sustainability, University of British Columbia, 2202 Main Mall, Vancouver, BC V6T 1Z4, Canada. ${ }^{2}$ Michael Smith Laboratories, University of British Columbia, 2185 East Mall, Vancouver, BC V6T 1Z4, Canada. ${ }^{3}$ Department of Psychology, University of British Columbia, 2136 West Mall, Vancouver, BC V6T 1Z4, Canada. Correspondence and requests for materials should be addressed to M.M.C. (email: meggie.

callahan@gmail.com)
} 


\section{Introduction}

urrent and ongoing news and research regarding biodiversity loss, local extirpations, and extinctions of wildlife species and populations have indicated that we now live amid an Anthropocene defaunation (Dirzo et al., 2014). Human actions involving land-use and climate change effects are reshaping biodiversity and causing homogenization of biological communities (Frishkoff et al., 2014; Brodie, 2016; Karp et al., 2018). Indeed, recent reports indicate that species extinction rates are dramatically increasing, and ecosystems are suffering due to human activities (Díaz et al., 2019). As serious as these problems are however, humans can also be part of the solution (Clayton et al., 2013). This is underscored by the significant attention now paid to engagement and education that contrasts with more pessimistic narratives which can lead to feelings of hopelessness (McKinley, 2008). Conservationists are consistently seeking new tools with which to motivate public knowledge and action, including media-driven games and movies, which can convey powerful messages and inspire action (Silk et al., 2017).

Another primary explanation for the current ecological crisis is incomplete knowledge and inadequate awareness of environmental problems, as a function of disconnection from local biodiversity (Kollmuss and Agyeman, 2010). Affiliation with nature has been shown to be associated with improved mood, increased physical health, and enhanced cognitive performance in humans (Hull and Michael, 1995; Bratman et al., 2012; Barton et al., 2016). However, despite this demonstrated vital connection, people, and notably children, are spending less time in nature and instead are consumed by other, more indoor-based pursuits (Louv, 2008). Soga and Gaston (2016) refer to this phenomenon as the "extinction of experience." It is postulated that urbanization has led to an increased alienation from and a decreased focus on natural ecosystems and biodiversity (Turner et al., 2004). This decreasing awareness of nature is starkly evident in a study of schoolchildren in the United Kingdom which found that children could name significantly more Pokémon characters than they could local species (Balmford et al., 2002).

In response, one key avenue linked to behavior change is education, or what is known as "ecoliteracy," improved understanding of natural systems (Orr, 1992; Goodwin, 2016; Fletcher, 2017). Ecoliteracy has led to an increased desire for sustainability and motivation to solve current environmental issues (McBride et al., 2013), including beneficial actions regarding biodiversity conservation.

Hubs of innovation for this purpose have included visual arts (Curtis et al., 2014), television (Dingwall and Aldridge, 2016), movies (Balmford et al., 2004), apps (Verma et al., 2015; Schuttler et al., 2018), as well as games (Fletcher, 2017). The argument, following Curtis et al. (2014), is that different forms of arts can influence environmental behavior through communicating information, creating empathy for the environment, and engaging in ecologically sustainable development. Millions of viewers see wildlife programs, for example, on television and in movies (Dingwall and Aldridge, 2016). Visual depictions of species increases interest and concern for those species (Smith and Sutton, 2008) and movies have the potential to influence people's perceptions towards endangered species (e.g., Spix's Macaw with the movie Rio) (Silk et al., 2017). Similarly, social media may be useful for understanding conservation behavior (Hausmann et al., 2017) and influencing knowledge about conservation (Papworth et al., 2015).

However, the rich visual information that media offers is still a passive form of communication and while it is consuming, it is not engaging. Little is known about more active forms such as games, that may promote biodiversity conservation or change people's perceptions of biodiversity. Research does indicate promise in that studies have suggested that people prefer games over other forms of education (Garris et al., 2002) and that games utilize experiential learning, an often more effective pedagogical tool than traditional didactic learning (Sandbrook et al., 2014). It is notable however that while most studies have focused on digital games (Fletcher, 2017), many do acknowledge the large quantity of players invested in collectable trading card games and their potential for ecological knowledge acquisition (Turkay et al., 2012; Fletcher, 2017).

One such trading card entity, the Phylo Trading Card Game (referred to as the Phylo game in this paper) has potential for investigating influence on knowledge and perceptions. It was designed in reaction to the aforementioned popularity of Pokémon, utilizes various cards featuring flora and fauna, and is a competitive two-player game focused on building ecosystems from a deck of cards (Ng, 2015). Since it is open platform in design, decks and cards are easily available (e.g., as free printyour-own formats and non-revenue generating purchasable decks) and many have been subsequently created including species from various geographical locations (e.g., Colombian Andean ecosystem, British Columbian Bryophyte, Danish Ice Age). Decks have been hosted by organizations such as museums and academic institutions focused on biodiversity and other STEM concepts (e.g., the Women in Science and Engineering deck) (Jones, 2018). A continual stream of new decks continues to be produced worldwide (http://phylogame.org) and thus provides a unique opportunity to explore an educational tool that has unlimited and global potential for raising awareness of biodiversity.

Given this potential, our objective here was to investigate whether the Phylo game is effective, and whether it positively impacts people's knowledge of species and ecosystems, as well as their attitudes and behaviors toward ecosystem or species conservation. Five research questions guided our work: (i) Does Phylo change people's dispositions (e.g., negative or positive) toward species; ecological perceptions (e.g., species' relationships to other ecosystem components); or economic perceptions (e.g., relative value of species)?, (ii) Does Phylo increase ecological knowledge about species (e.g., their diet or habitat)?, (iii) Do participants experience more positive affect (related to personal emotions) when playing Phylo vs. when learning information via a more traditional way (e.g., lecture-style slideshow)?, (iv) Does Phylo impact conservation donation behavior?, and (v) Does Phylo increase people's recall or memory retention of species over and above those listed in a pre and post-intervention survey? We predicted that Phylo had the potential to increase positive ecological perceptions of and positive dispositions for species, ecological knowledge of species, donation behavior toward endangered species and negative environmental events, positive affect, and memory of species.

\section{Methods}

We used a before-and-after-control-impact design in a laboratory setting between March and November 2017 to examine how people's perceptions and knowledge of species and their subsequent donation behavior changed after playing the Phylo game. To do so, we designed an experiment with three conditions: Phylo, Slideshow, and Projects to which participants were assigned randomly. The Phylo condition referred to those participants who played the Phylo game in pairs. The Slideshow condition was designed to be an information control and referred to a more traditional form of learning, in the form of a PowerPoint lecture. The other control was the Projects condition and was used as a game control where paired participants actively played a similar game, but one that did not focus on biodiversity conservation. 
Participants. To determine the sample size, we conducted an $a$ priori power analysis using Power and Sample Size (http:// powerandsamplesize.com). Our power analysis was calculated with the following parameters: probability of a no event-event $\left(\mathrm{P}_{01}\right)=0.4$, probability of event-not event $\left(\mathrm{P}_{10}\right)=0.6$, alpha $=0.05$, power $=0.8$, three between-subject groups, and two within-subject groups. According to the power analysis we needed a minimum of 194 participants in total to detect differences across conditions and determined that a sample size of at least 68 participants per condition would be sufficient. Based on this number we designed our experiment.

Overall we recruited 209 participants, both graduate and undergraduate students from the University of British Columbia (UBC) (123 female, 83 male, 2 other, 1 preferred not to answer; mean age $(\mathrm{SD})=21.6(4.8))$. The students were predominantly recruited through the Human Subject Pool (HSP) in the Department of Psychology and completed the study in exchange for course credit. Additional students were recruited through other departmental listservs (e.g., Zoology, Earth and Ocean Sciences, Forestry).

Participants were run in pairs by a researcher and each pair was randomly assigned to one of three conditions prior to their arrival to the lab: the Phylo condition ( $n=70$ people, $n=35$ pairs), where participants played the Phylo game using the Beaty Biodiversity Museum Deck, the Slideshow condition $(n=71)$ where participants viewed a PowerPoint slideshow using the Phylo cards on a computer, and the Projects condition $(n=68$ people, $n=34$ pairs) where participants played a separate card game using a deck created by the Genetic Society of America. If a participant failed to show up for the Phylo or Projects condition, the researcher would run the other person singly in the Slideshow condition.

Justification for a student sample. Sampling students is a widely accepted practice in psychology. We acknowledge that using only a student sample has its limitations, however we felt this was an applicable population for a number of reasons. The game is marketed for ages $8+$ and indeed is sold on campus at the Beaty Biodiversity Museum, thus making students possible purchasers and users of the game. In addition, the general age of the students sampled place them in the category of the population who experienced the height of the Pokémon popularity phase, and as such it is interesting to note their subsequent interactions with trading card games, along with species identifications. Finally, college-age individuals are often of interest to conservation organizations due to their ability to be influenced as they seek to understand their own self-identities (Arnett, 2012).

\section{Stimuli and procedure}

1. Pre-survey. Participants in all three conditions completed the same pre survey on the computer using Qualtrics (Qualtrics LLC, 2005). The pre survey contained questions on perceptions and knowledge about four focal species, affect, and intended donations. Participants were first asked questions regarding their dispositions towards and ecological and economical perceptions of the species, as well as questions about their knowledge of those species. Ecological perceptions were measured as the understanding of species and their relation to their respective ecosystems. Economic perceptions related to participants' views on the importance of a species as a resource for human economic needs. What we refer to here as dispositions is a measure of participants' preference for and liking of different species. We asked two questions regarding participants' knowledge of species, one pertaining to the species' diet (carnivore, autotroph, etc.) and one pertaining to the environments in which the species could be found (forests, grasslands, etc.). Additionally, participants were asked qualitative open-ended questions broadly focused on each species (e.g., "What comes to mind when you think of Clark's Nutcrackers?"). All information could be found on the Phylo cards. Open-ended questions have been credited with revealing additional information and emotive reactions that the Likert scale items do not capture, thus they provide complementary data to quantitative methods (Slovic et al., 2007). (See supplementary material for a copy of the survey).

The four focal species in the survey were: Clark's Nutcracker (Nucifraga columbiana), three-spined stickleback (Gasterosteus aculeatus), earthworm (Lumbricus terrestris), and giant kelp (Macrocystis pyrifera) (Fig. 1). The four focal species were selected because they are all found in the Phylo Beaty Biodiversity Museum starter deck, they represent a range of different trophic levels, diets, and environments, and are not generally considered overly iconic or charismatic, which can induce ceiling effects (Echeverri et al., 2017).

Additional questions in the pre survey included the Positive and Negative Affect Schedule (PANAS scale) (Watson et al., 1988), and questions to measure intended donations to either conserve one of the four species, conserve an environment (grassland, ocean, or forest), prevent/clean up after an event (climate change, wildfire, oil spill), or keep the money for oneself.

2. Experimental conditions. When both participants finished the pre survey, they continued the experiment in their respective condition. Those in the Phylo condition were taught the Phylo card game with the Beaty Biodiversity Museum starter deck that focuses on native British Columbian species and environments. They then played the card game against one another. The researcher only reiterated the rules or answered questions about what was permissible. They did not comment on strategy or otherwise engage with the game. When the game finished, the points were tallied and the winner was given a "toonie" (CAD\$2), and the loser a "loonie" (CAD\$1).

Those in the Projects condition were taught a different Phylo card game, created by the Genetic Society of America that focused on accumulating resources to complete scientific "projects." This condition served as a control for the act of playing a game since it was a two-person competitive card game in the same vein as Phylo but was not based on building ecosystems and did not feature any of the species from the Phylo game. As with the Phylo condition, those in the Projects condition played the game against one another with the researcher only providing rule-based information. At the conclusion of the game the winner was given $\mathrm{CAD} \$ 2$ and the loser CAD $\$ 1$.

Those in the Slideshow condition were given access to a slideshow on a computer that they could advance at their own pace. The slideshow used images of the Phylo cards to explain different trophic levels, different ecosystems, and different environmental events. All the cards available in the deck were shown in the slideshow. Afterwards, participants were given a chance to look through the deck but did not play the Phylo game and did not interact with their partner. All single participants were placed in the Slideshow condition. After the pair completed the slideshow and looked through the deck one participant was randomly given CAD $\$ 2$ and the other CAD $\$ 1$. Single participants were also randomly assigned either $\mathrm{CAD} \$ 2$ or $\mathrm{CAD} \$ 1$.

3. Post-survey. At the end of the game or slideshow, participants in all three conditions completed the post survey on the computer using Qualtrics. The post survey contained the same questions as in the pre survey, except there was no question regarding donation intention. In addition, a range of demographic questions and some qualitative questions regarding memories of the game and 
(a)

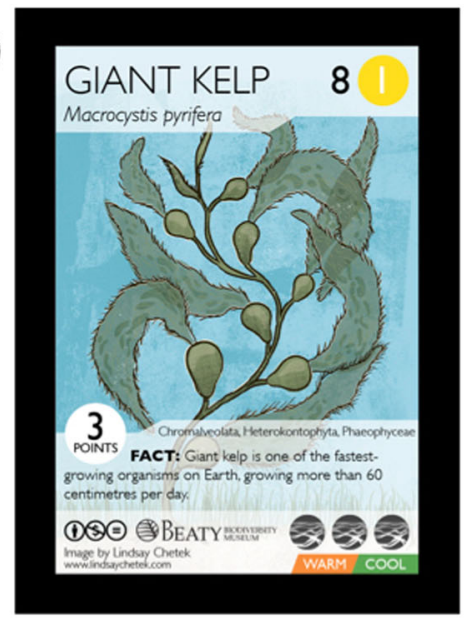

(c)

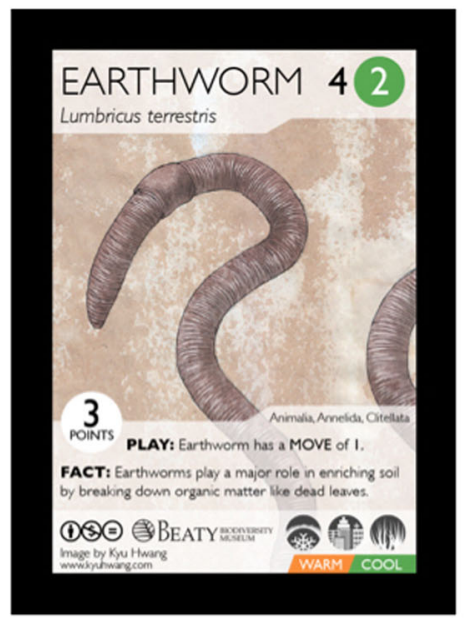

(b)

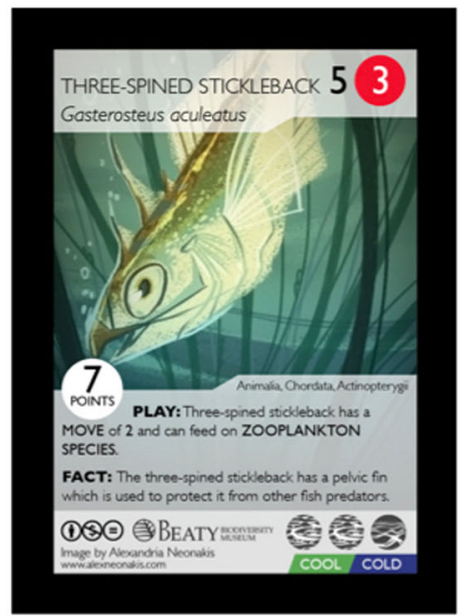

(d)

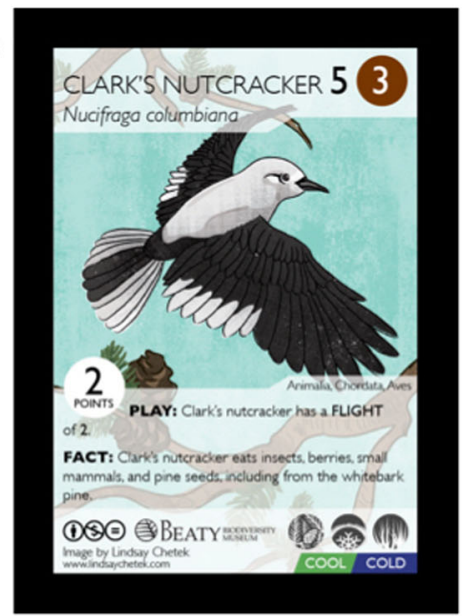

Fig. 1 Pictures of Phylo cards from the Beaty Biodiversity Deck featuring the four different species used in the pre and post survey (a) giant kelp (Macrocystis pyrifera), (b) three-spined stickleback (Gasterosteus aculeatus), (c) earthworm (Lumbricus terrestris), and (d) Clark's Nutcracker (Nucifraga

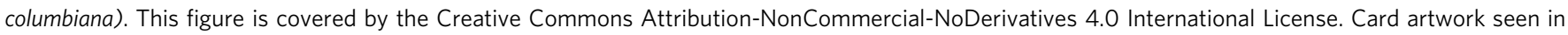
figure by Lindsey Chetek, Alexandria Neonakis, and Kyu Hwang

specific species were included at the end of the post survey. Specifically, we asked: "Which one species do you most remember from the Phylo game (or the Slideshow)?" The survey was the same across the three conditions, except participants in the Projects condition were not asked about which species they recalled, as the card game used in the Projects condition did not contain the species found in the Phylo or Slideshow conditions.

4. Donation. After completing the post-survey, one participant at a time was taken out of the testing room and debriefed by the researcher about the purpose and design of the study. (Although information on the future tasks such as donation was not revealed at that time). Afterwards, participants were asked if they would like to donate their earnings from the game (a CAD $\$ 1$ or CAD $\$ 2$ coin) to conserving one of the four focal species, one of three ecosystems, or preventing one of three negative environmental events by placing the coin in an opaque sealed box (see Fig. 2, Fig. S1). The order of the boxes was randomized for each pair of participants, though the same 10 boxes were displayed each time. We placed four coins in each box a priori, so that participants would not be biased toward empty or more full boxes. Participants were accurately told that a donation would be made at the end of the study depending on which species, ecosystem, or event had received the most money, but were also explicitly told that the coin was theirs and they were free to do with it what they wished, including keeping it for their own use. All boxes were checked after each study and coins removed to ensure each box had an equal number of coins when participants were donating. For the analysis, we sorted the donation possibilities into four categories: Ecosystems (conserve grassland, conserve forest, conserve ocean), Events (prevent/clean oil spills, prevent/fight wildfires, prevent climate change), Species (conserve three-spined stickleback, conserve earthworm, conserve Clark's Nutcracker, conserve giant kelp), and No Donation.

5: Follow-up survey. One month after they had completed the inperson part of the study, participants were emailed a follow-up survey using Qualtrics. They had been apprised that this would be occurring during the debrief and were asked to fill out the followup survey. The follow-up survey was identical to the post survey, but without the additional demographic questions. The total number of survey responses were low: Phylo $(n=23)$, Projects $(n=21)$, and Slideshow $(n=17)$.

\section{Data analysis}

1. Quantitative analysis. A confirmatory factor analysis was used to test that our questions were indeed measuring three separate constructs: ecological perceptions, economic perceptions, and dispositions towards species. Upon confirmation of the three 


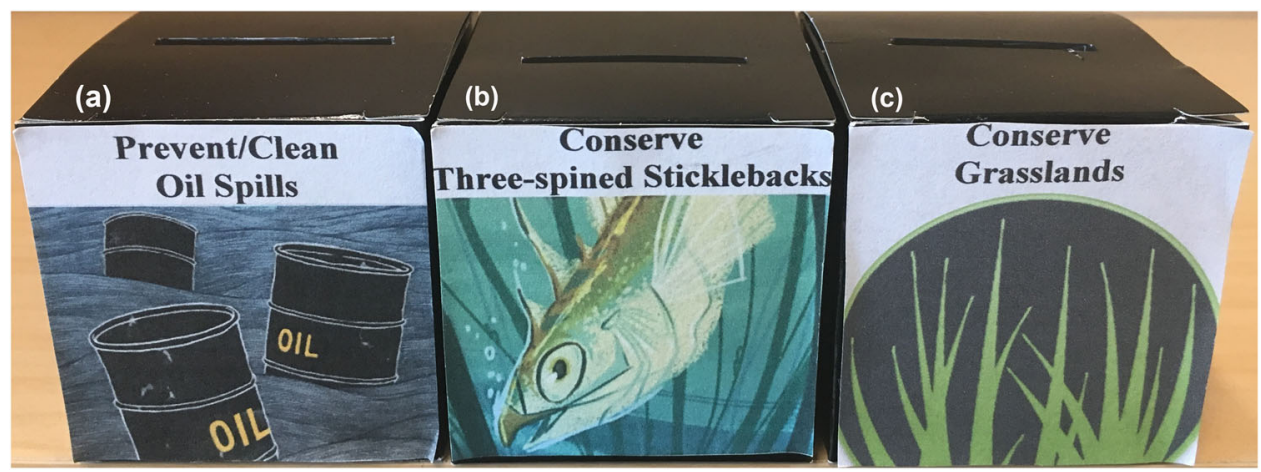

Fig. 2 Example of the boxes used for collecting donations from participants. The boxes were a set of issues: event-focused such as (a) Prevent/Clean Oil Spills; species-focused such as (b) Conserve Three-spined Sticklebacks; and ecosystem-focused such as (c) Conserve Grasslands

factors, we then pooled all items into each of the three categories and summed the scores. We used these summed scores as response variables in subsequent analyses. All statistical analyses were conducted in the statistical software $\mathrm{R}$ version 3.4.1 and Excel.

To examine our first question, (whether Phylo impacted people's perceptions of species), we first ran three-way mixeddesign ANOVAs (Species $\times$ Condition $\times$ Time). Species refers to the four focal species and is a within-subjects factor. Condition refers to the three experimental conditions and is a betweensubjects factor. Time refers to pre vs. post comparison and is a within-subjects factor. We then conducted post-hoc t-tests to detect significant differences between individual conditions. We applied Bonferroni corrections to all $p$ values with scores $<0.05$ to minimize type I errors. We also calculated partial eta squared $\left(\eta_{p}^{2}\right)$ and Cohen's $\mathrm{d}$ as measures of effect size. Additionally, we calculated the difference between pre and post scores on ecological and economic perceptions, and dispositions and conducted one-way ANOVAs to assess the impact of condition on such differences. Then, we used Tukey HSD post-hoc tests for pairwise comparisons.

To examine our second question, (whether Phylo increased ecological knowledge about species), we first calculated knowledge scores for each of the two knowledge questions. Participants were scored either 1 (correct) or 0 (incorrect) on questions regarding the diet of species (e.g., autotroph, herbivore) for both the pre and post survey. For questions regarding the environment of the species, the participants' scores were a proportion of correct responses over the total possible correct responses, thus participants were scored between 0 (no correct responses) and 1 (all correct responses selected), and we evaluated participant's total accuracy. We then conducted three-way mixed-design ANOVAs (Species $\times$ Condition $\times$ Time), post-hoc t-tests, and calculated Cohen's d.

To examine our third question, (whether participants experienced positive affect when playing Phylo), we conducted a two-way ANOVA (Condition $\times$ Time) on scores from the Positive and Negative Affect Schedule (PANAS scale), a measure of personal positive and negative emotional states (Watson et al. 1988). The scale was split into positive and negative affect. We also conducted post-hoc $t$-tests, and calculated partial eta squared $\left(\eta_{p}{ }^{2}\right)$ and Cohen's $\mathrm{d}$. We also calculated a one-way ANOVA to test the effect of condition on the difference in affect scores in the post and the pre surveys, and used Tukey HSD as post-hoc tests.

Lastly, to examine our fourth question and test whether there was a difference in donation across the three conditions we ran two chi-squared tests on the donation intentions in the pre survey and the actual donations after the game or slideshow.
2. Qualitative analysis. Open-ended questions were analyzed using non-hierarchical axial coding for each species and condition. Codes were derived from the participants' responses and identified using 7 categories presented in Table S1 (e.g., ecological importance, species' attributes, species' environment). We assigned each response or part of a response to a category and performed two rounds of coding to ensure accuracy. We then counted the frequency of occurrence for each category. For each condition (Phylo and controls) we conducted chi-squared tests to evaluate the statistical differences between the pre and post counts. We also analyzed answers from the final survey question "Any other comments?" as well as comments stated verbally to researchers throughout the experiment to determine general positive attitudes across the conditions (i.e., statements of fun/ enjoyment/liking).

To examine our fifth question, (whether Phylo increased people's recall or memory retention of species), we counted the frequency of different species mentioned in the final question of the post survey and performed a chi-squared test to evaluate the effect of condition on species recall. Lastly, we calculated the percentage of species that were mentioned in the survey.

\section{Results}

Perceptions. Regarding ecological perceptions of species (i.e., the perceived relationship of species to their ecosystems), we found a significant main effect of condition (Phylo, Projects, or Slideshow condition) on responses $\left(F(2,206)=3.54, p<0.05, \eta_{p}^{2}=0.03\right)$. The post-hoc t-tests with Bonferroni corrections revealed that both the Phylo and Slideshow conditions significantly increased ecological perceptions from pre to post survey (Phylo: $t(279)=$ -3.90, $p_{\text {adj }}<0.001, d=-0.21$ and Slideshow: $t(283)=-4.57$, $p_{\text {adj }}<0.0001, d=-0.03$ ) (Fig. 3). Results from the one-way ANOVA indicated that condition had an effect on changing ecological perceptions (i.e., difference in scores of post-pre) $(F$ $(2833)=5.49, p<0.05)$. Tukey HSD tests revealed that Phylo and Slideshow had the same effect on ecological perceptions $\left(p_{\text {adj }}=0.77\right)$. Projects was different than Phylo $\left(p_{\text {adj }}=0.04\right)$ and Slideshow $\left(p_{\mathrm{adj}}=0.004\right)$ as both had a stronger impact on increasing ecological perceptions than Projects.

For the economic perceptions (i.e., the relative importance of species to economies) we also found that there was a significant main effect of conditions $\left(F(2,206)=7.67, p<0.001, \eta_{p}^{2}=0.07\right)$. The post-hoc t-tests revealed that the Projects condition significantly increased economic perceptions from pre to post $\left(t(271)=-3.78, p_{\text {adj }}<0.01, d=-0.14\right)$, while they were not different for the Slideshow or Phylo Conditions $\left(p_{\text {adj }}>0.05\right)$ (Fig. 3). One-way ANOVA results indicated a significant effect of condition on the difference between post-pre scores 
(a)

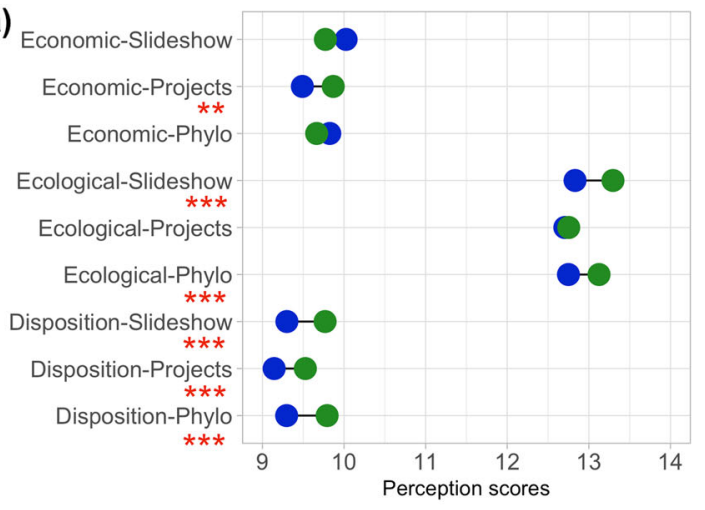

(c)

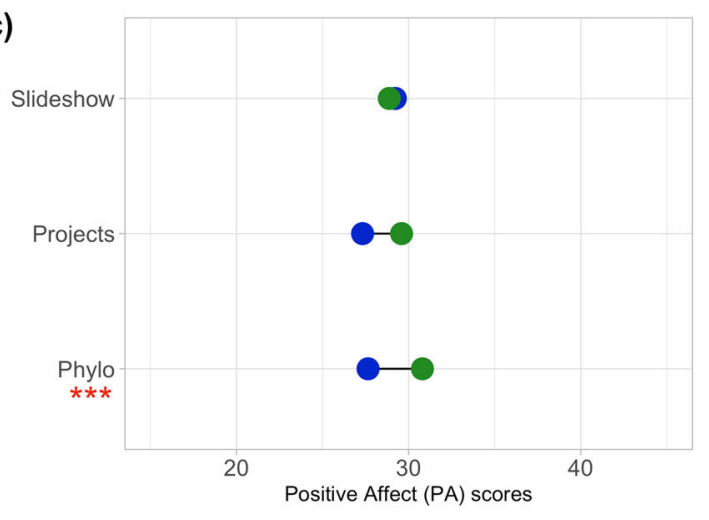

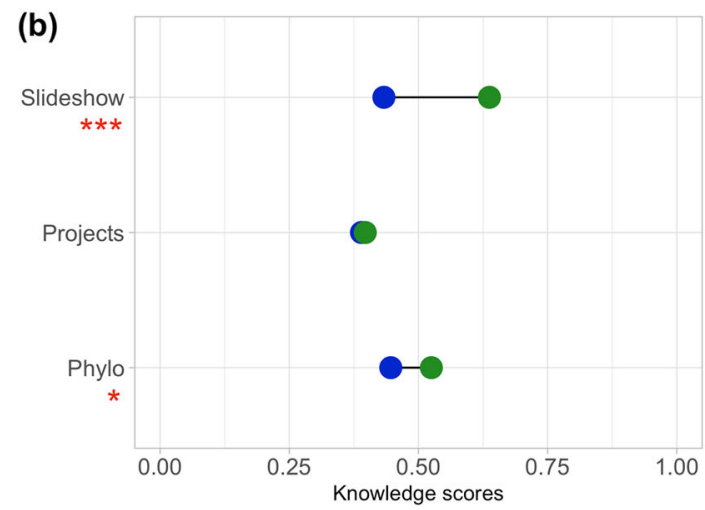

(d)

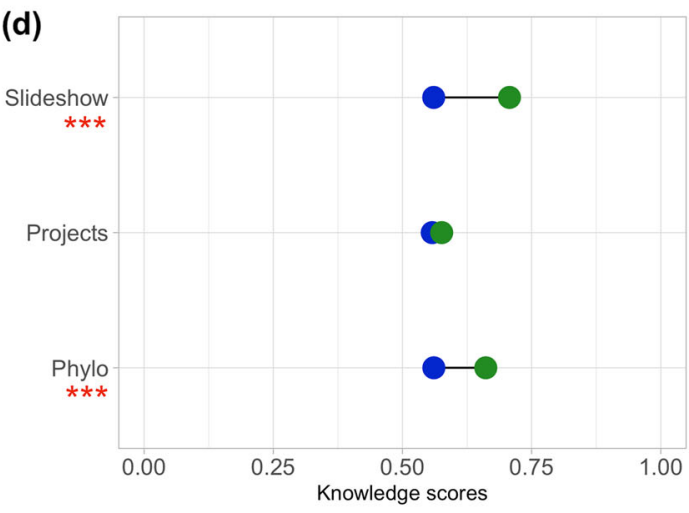

Pre Post $\quad{ }^{*} \mathrm{p}<0.05{ }^{* *} \mathrm{p}<0.01{ }^{* * *} \mathrm{p}<0.001$

Fig. 3 Lollipop graphs showing the results of (a) changes in economic perceptions, ecological perceptions, and dispositions across conditions, (b) changes in participants' knowledge of species environments across conditions, (c) changes in participants' positive affect across conditions, (d) changes in participants' knowledge of species diets across conditions. The blue circles represent the mean value of the pre survey and the green circles represent the mean value of the post survey. Significance level is indicated by the red asterisks underneath the name of each condition on the left of the graphs in the following order of significance ${ }^{\star} p<0.05$; ${ }^{\star \star} p<0.01 ;{ }^{\star \star \star} p<0.001$. Three conditions are represented: Phylo $(n=70)$, Projects $(n=68)$, and Slideshow $(n=71)$

$(F(2833)=10.37, p<0.0001)$. Tukey HSD tests revealed that Phylo and Slideshow had the same effect on economic perceptions $\left(p_{\text {adj }}=0.81\right)$. Projects was different than Phylo $\left(p_{\text {adj }}\right.$ $<0.001)$ and Slideshow $\left(p_{\text {adj }}<0.0001\right)$ as both decreased economic perceptions in the post condition.

Lastly, regarding dispositions toward species, there was no main effect of conditions $\left(F(2,206)=0.65, p=0.52, \eta_{p}^{2}=0.01\right)$. However, we found a significant main effect of time (increasing from pre to post) in all three experimental conditions $(F(1$, $206)=49.29, p<0.0001, \eta_{p}^{2}=0.19$ ) (Fig. 3). One-way ANOVA results indicated no significant effect of condition on the difference between post-pre scores $(F(2833)=0.39, p=0.68)$.

Knowledge. We found a significant difference in the three conditions regarding knowledge of species diet $(F(2,206)=10.10$, $\left.p<0.001, \eta_{p}^{2}=0.08\right)$. The post-hoc t-tests showed that both the Phylo and Slideshow conditions significantly increased people's knowledge on diets from pre to post (Phylo: $t(279)=-2.48, p_{\text {adj }}$ $<0.05, d=-0.16$; Slideshow: $t(283)=-5.97, p_{\text {adj }}<0.0001, d=$ $-0.02)$, whereas the Projects condition had no significant change (Projects: $\left.t(271), p_{\text {adj }>0.05}, d=0.01\right)$. A similar result was found regarding knowledge on the species' environments where there was a significant difference in the three conditions $(F(2$, $\left.206)=4.57, p<0.05, \eta_{p}^{2}=0.07\right)$. The Phylo and Slideshow conditions significantly increased from pre to post (Phylo: $t(279)=-5.19, \quad p_{\mathrm{adj}}<0.001, d=-0.32 ;$ Slideshow: $t(283)=$
$-7.30, p_{\text {adj }}<0.001, d=-0.06$ ) (Fig. 3). We also found that participants in the Slideshow condition exhibited higher accuracy, which is the number of correct answers, in their responses of ecological knowledge of species $(71.73 \%$ of correct responses about diet vs. $66.13 \%$ for Phylo vs. $55.95 \%$ for Projects and $64.64 \%$ of correct responses about environment vs. $52.50 \%$ for Phylo vs. $38.57 \%$ for Projects).

Affect. There was a significant main effect of condition for positive affect $\left(F(2,206)=4.69, p<0.05, \eta_{p}^{2}=0.04\right)$ (Fig. 3), but not for negative affect $\left(F(2206)=0.065, p>0.05, \eta_{p}^{2}<0.001\right)$ (supplementary material Fig S2). Specifically, post-hoc $t$-tests showed that the Phylo condition significantly increased positive affect from pre to post $\left(t(69)=-3.72, p_{\mathrm{adj}}<0.001, d=-.40\right)$ and Projects was marginally significant $\left(t(67)=-2.28, p_{\text {adj }}=0.07\right.$, $d=-0.28)$, while the Slideshow condition did not have a significant impact on positive affect $\left(t(69)=0.51, p_{\text {adj }}>0.05\right.$, $d=0.05$ ) (Fig. 3). One-way ANOVA results indicated that condition had an effect on the difference of positive affect scores (i.e., difference between post and pre $)(F(2206)=4.68, p<0.05)$. Tukey HSD tests revealed that Phylo and Projects had the same effect on positive affect $\left(p_{\text {adj }}=0.74\right)$. Slideshow was different than Phylo $\left(p_{\mathrm{adj}}=0.01\right)$ and Projects $\left(p_{\mathrm{adj}}=0.08\right)$ as both had a stronger impact on positive affect than Slideshow. One-way ANOVA results indicated no significant differences on the effect 

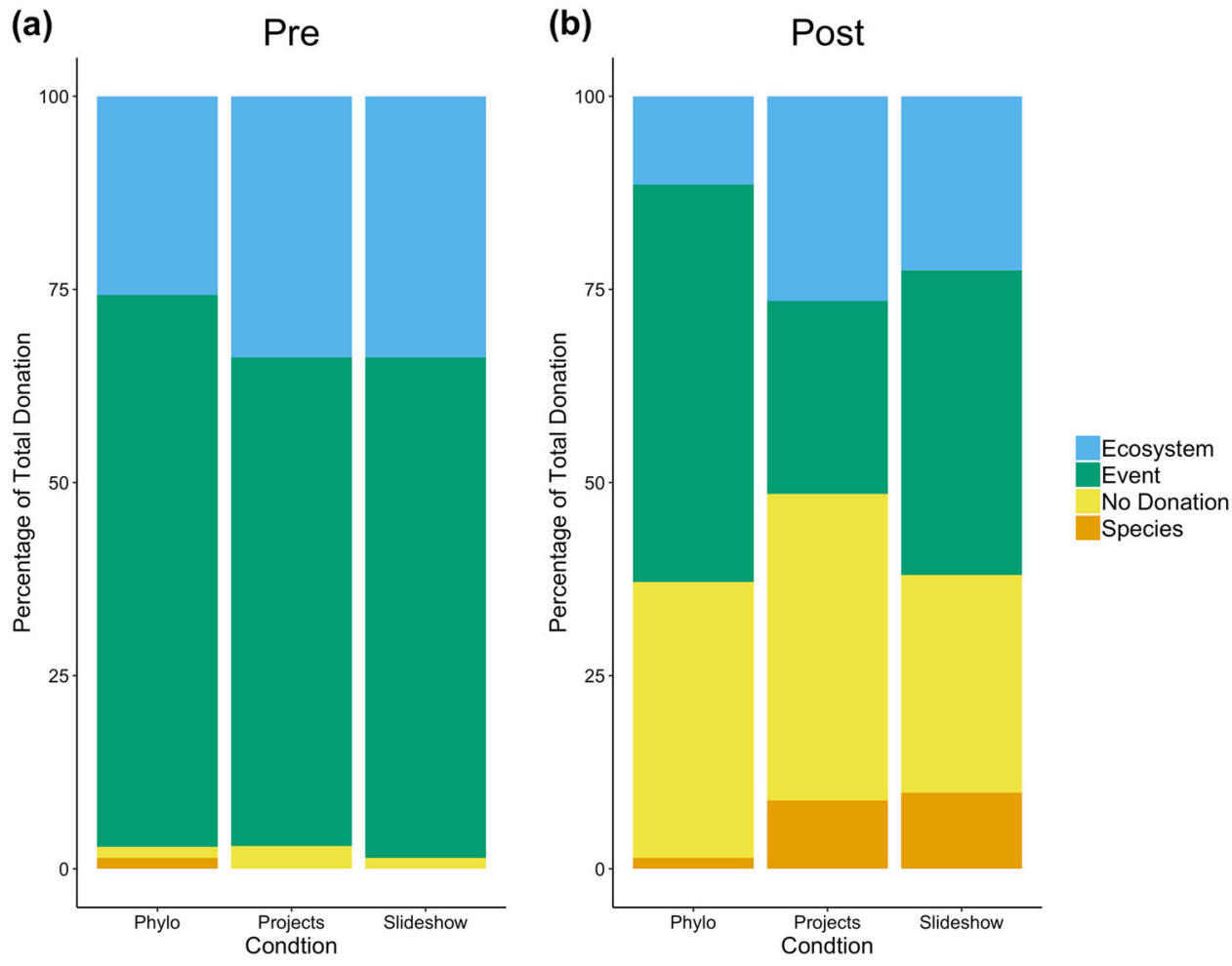

Fig. 4 Bar graphs showing the percentage of total donation to each of the four donation categories (i.e., conserve ecosystem, prevent negative environmental event, no donation, conserve species) for each experimental condition (i.e., Phylo, Projects, Slideshow) in the (a) pre and (b) post periods

of condition on the difference of negative affect between post and pre conditions $(F(2206)=0.065, p=0.94)$.

Donation behavior. Chi-squared results indicated that for the pre survey, there were no associations between conditions and donation categories $\left(\chi^{2}(6)=3.9, p=0.68\right)$. However, after playing the game or seeing the slideshow, chi-squared results revealed a significant association between conditions and donation categories $\left(\chi^{2}(6)=16.2, p=0.01\right)$. Specifically, we found that in the Projects condition, participants donated significantly less to events than expected by chance. We also found that in the Phylo condition, participants donated significantly less to ecosystems and species, and significantly more to events than expected by chance. Additionally, no donation increased in all three conditions in the post data (Fig. 4).

Qualitative data. We found significant differences between the pre and post survey responses in regards to the category: "Ecological" label $\left(\chi^{2}(2)=19.67, p<0.0001\right)$. Slideshow participants at the post-survey stage had more ecological responses than expected by chance, and Projects participants had less than expected by chance. Phylo did not have a significant change from pre to post $(p>0.05)$, but it trended upwards (more ecological responses post than pre) (supplementary material Tables S1 and S2). After analyzing the "Any other comments?" and the verbal statements to the researchers, we found that participants in the Phylo and Projects conditions expressed more fun and enjoyment than those in the Slideshow condition (Table S3).

Species recall. Species recall in the Phylo condition included 76\% of the total number of species featured in the game (19 different species remembered of 25 total in the Phylo game). In the Slideshow condition participants remembered $56 \%$ of the total number of species in the Phylo game (14 species remembered).
The difference between Phylo and Slideshow was not significant $\left(\chi^{2}(1)=0.67, p=0.41\right)$, given the small sample size of total species.

We also examined how frequently any of the four focal species, featured in the pre and post surveys, were mentioned as compared to species not featured in the surveys. The majority of species remembered $(83.58 \%)$ by Phylo participants were not featured in the survey. In the Slideshow condition only $29.85 \%$ of the species remembered were ones not found in the survey (Fig. 5). The difference between the experimental condition (Phylo) and Slideshow regarding species remembered and featured in the survey versus not featured in the survey was significant $\left(\chi^{2}\right.$ $(1)=37.24, p<0.001)$.

Follow-up survey responses. In our follow up survey, Phylo participants $(n=23)$ remembered 12 species, and Slideshow participants $(n=17)$ remembered 6 species (Fig S3), a difference that was not significant $\left(\chi^{2}(1)=2.17, p=0.14\right)$. Again, the majority of these remembered species $(82.61 \%)$ for Phylo participants were ones not featured in the survey. In comparison, only $11.76 \%$ of Slideshow participants' answers were ones not featured in the survey, which indicates a significant difference $\left(\chi^{2}\right.$ $(1)=16.94, p<0.001)$.

\section{Discussion}

The current study demonstrated that both the Phylo game and the slideshow had a significant positive impact on participants' ecological perceptions of species and participants' knowledge about species. More importantly, the Phylo game also promoted positive affect, facilitated species recall after the game, and increased donations to environmental events (i.e., prevent/clean oil spills, prevent/fight wildfires, prevent climate change).

Enhanced ecological perceptions indicate participants' increased beliefs that the species are important to the ecosystem in which they live. This result supports the idea that different 


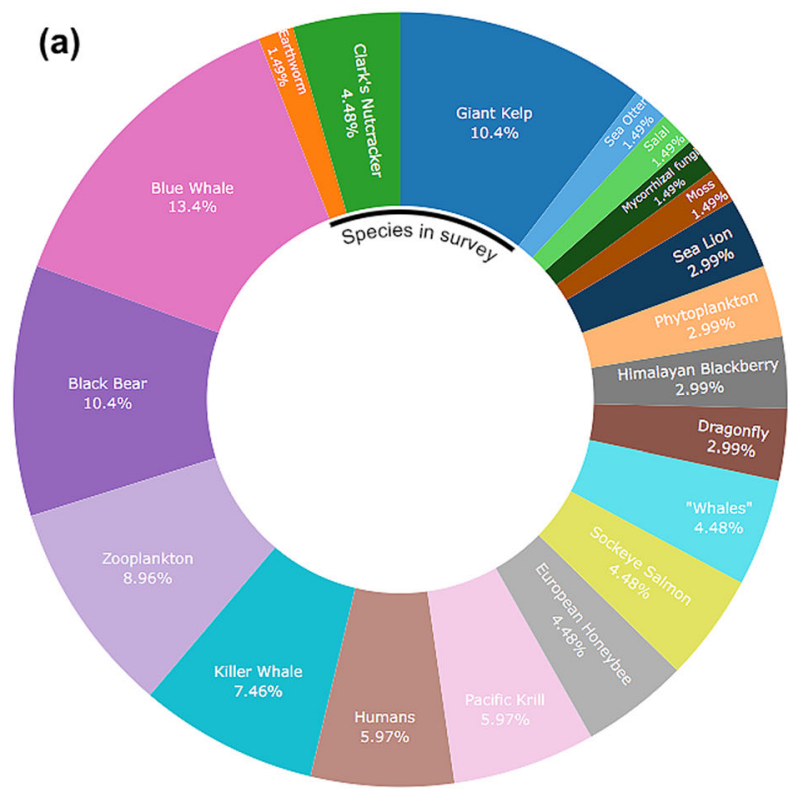

Phylo

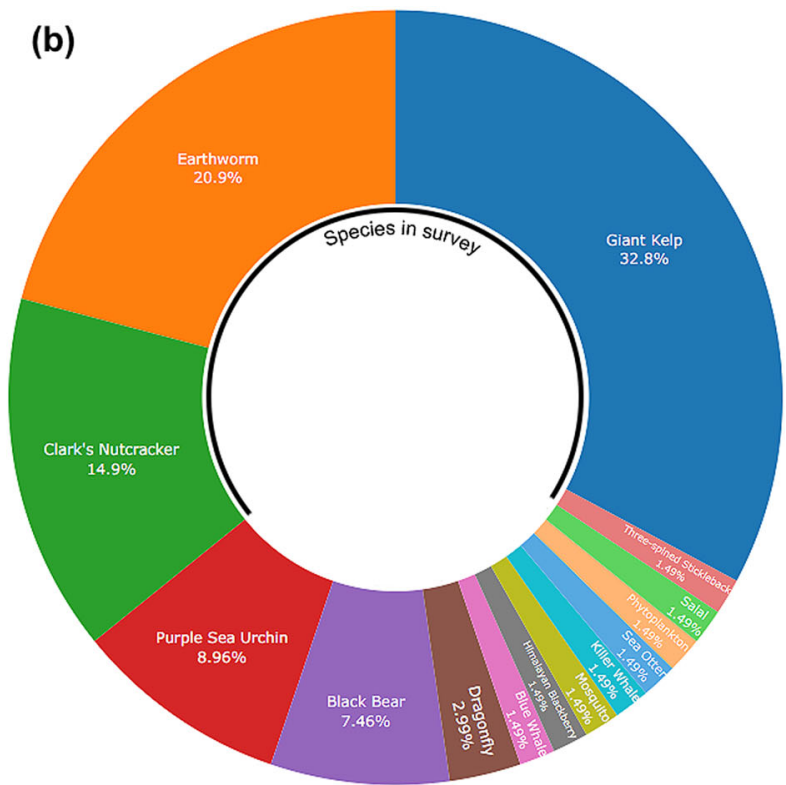

Slideshow

Fig. 5 Donut graphs showing the species participants most recalled from (a) the Phylo game $(n=70)$, or $(\mathbf{b})$ the Slideshow ( $n=71)$ at the end of the post survey. Black lines in the center of the graphs indicate species that were featured in the surveys

conservation-based tools (such as games) have the potential for increasing ecoliteracy and aiding conservation education (Brewer, 2003). Furthermore, the fact that the Phylo game had similar results to the slideshow in some categories (e.g., ecological perceptions, knowledge of species' diets and environments), which is arguably a more traditional form of imparting information, suggests that the Phylo game could be used as a potential substitution for didactic learning as well. One important caveat is that Slideshow participants still had higher knowledge accuracy scores. This could be due to the fact that current university students are taught primarily via lectures often with the use of slideshow presentations (Laurillard, 2013), so the familiarity with this format may have facilitated learning.

The monetary value of species (what we here call economic perceptions), was comparatively higher in the Projects condition; participants rated species as significantly higher in terms of their relative importance to economies in the post survey. Similar trends were not exhibited by participants in the Slideshow or Phylo conditions. This finding may be explained by the fact that the species cards in the slideshow and the Phylo card game did not emphasize any kind of economic value of the species. However, in the card game used in the Projects condition, species cards (i.e., zebrafish, and frog) were used as resources to complete projects. In addition, the game features cards such as "Grant approved" or "Lose funding" that serve to place greater emphasis on economic concerns (Swanson, 1994). Together these may explain why Project participants ranked the economic value of species as higher after playing the game.

Dispositions toward species were not impacted by the experimental condition, but rather by time (pre vs. post). This was evidenced by the fact that affinity for species was significantly higher in all of the post responses than the pre survey responses, indicating a greater affinity for species after each condition. This may be a result of increasing familiarity with the species, given that participants saw the same species multiple times across the different conditions and surveys. Familiarity of species has been shown to increase liking for the species (Amiot and Bastian, 2015; Echeverri et al., 2017).

The Phylo game significantly increased participants' positive affect overall, a finding also marginally significant for Projects participants. In addition, participants in both games expressed higher levels of fun and enjoyment than those in the Slideshow condition. Participants verbally stated this to the researchers as well as writing comments in the survey (e.g., "The game was quite fun to play," "I like the game! Wish we could play a few more rounds"). These are notable results due to the fact that more enjoyable pursuits increase motivation to engage further with them, which has been noted as the first step toward learning (Paras and Bizzocchi, 2005). Indeed, a game that is deemed "fun" is more likely to be played and thus more likely to have an effect than the opposite (Sweetser et al., 2012).

Assessing participants' actions after the game, such as donation behavior, was used to determine any additional positive impact of the game. We found all conditions increased in No Donation in the post data, though this may be due to our sample being comprised mostly by students who have no extra money to spare. These results might differ if other populations are sampled. Nonetheless, we found that in the Phylo condition, the amount donated to prevent environmental events such as climate change, wildfires, and oil spills was significantly higher than would be expected by chance. However, donations to species and ecosystems were less than expected by chance. These results may be due to the impact such cards have in the game. Event cards often cause the destruction of entire ecosystems (when played on low trophic level cards) or the extinction of iconic species and are usually the main cards that lead to either winning (if played on the opponent) or losing the game (if one receives the card). In the game, by stopping a single event, participants were often able to save ecosystems and species. Thus, the game potentially taught our participants that preventing events may lead to better conservation outputs and this may help explain why in the post condition participants donated less to species and ecosystems and more to events. 
This result also makes the Phylo game of interest to conservation organizations as a potentially useful tool for promoting donation toward the prevention of environmental threats. Our results also indicate that dystopian content is not necessarily at odds with utopian scenarios. The game not only highlighted both dystopic threats (e.g., climate change) and their magnitude as they concern biodiversity (Slovic et al. 2004), but also engaged people in ways that were fun. Such motivational contexts (as opposed to content) about ecosystems and biodiversity issues may then still contribute to hopeful rather than hopeless feelings about these topics (McKinley, 2008).

The high rate of species remembered that were not in the survey indicates that those playing the Phylo game were recalling species from playing the game itself. The follow up surveys, despite their low return rate, echo this finding. Indeed, the responses for the Phylo condition participants in the follow up surveys included responses of "Himalayan Blackberry" and "Western Honey Bee" as opposed to just "blackberry" or "bee," suggesting their retention was not necessarily due to its familiarity, but due to the game itself. This finding emphasizes the ability of the game to encourage memory retention of species akin to the Pokémon game, where detailed characters are common. This also verified the primary expectation behind creating the game itself as its intent was to create a tool that would promote ecoliteracy $(\mathrm{Ng}, 2015)$.

Balmford's et al. (2002) observation that children had greater recognition of, and therefore a presumed predilection for, Pokémon characters rather than local flora and fauna is sobering. Indeed a recent study that evaluated the benefits of Pokémon Go echoed the results from Balmford et al. (2002), stating that conservation continues to lag behind Pokémon (Dorward et al., 2017). As interactions with wilderness are replaced by more virtual interactions, those concerned about the so-called extinction of experience, (Louv, 2008; Soga and Gaston, 2016) may yet find hope in such under-explored options as putting gaming potential to good use. The utilization of a "Pokémonesque" trading card system, like the Phylo game, may hold real value in increasing ecoliteracy in a relatable and enjoyable fashion. The Phylo game, as demonstrated here, has potential for increasing ecoliteracy regarding local biodiversity, for raising awareness of environmental issues, and for motivating people to donate to the mitigation of environmental threats. Phylo is also an open-source and creative commons game that can be easily adapted to other geographical contexts and thus is widely available for environmental knowledge enhancement and communication.

We also consider the Phylo game as a complementary strategy to other emerging initiatives such as citizen science projects (e.g., iNaturalist, eMammal, eBird, Project BudBurst) for raising awareness on biodiversity and hopefully reversing the extinction of experience (Dickinson et al., 2012, Schuttler et al., 2018). But some citizen science projects are likely more useful for certain situations and for people with access to and interest in technology. On the other hand, the Phylo game might be welcomed and used to engage other audiences, such as those limited by nonexistent or incomplete access to or familiarity with screenbased media. Future research could replicate our study with any of the other decks that have been designed, to test for the generalizability of our results within other populations. Moreover, a study comparing various methods, such as the aforementioned games, movies, and citizen science apps designed to increase ecoliteracy would also be important to consider for future research.

At a time when conservationists need to engage more broadly with the public and motivate engagement with global threats to biodiversity (Butchart et al., 2010), we suggest the importance of bringing more attention to enjoyable and educational games.
They can serve as novel and effective tools to help advance the achievement of common conservation goals. We acknowledge that games alone are not a "panacea," but they may provide an important adjunct to other efforts to increase ecoliteracy, motivate environmental citizenship, and contribute to more affinity with the natural world and ecosystems undergoing rapid anthropogenic change.

\section{Data availability}

The datasets generated during the current study are not publicly available due to participant confidentiality, but are available from the corresponding author upon reasonable request.

Received: 7 January 2019 Accepted: 24 June 2019

Published online: 16 July 2019

\section{References}

Amiot CE, Bastian B (2015) Toward a psychology of human-animal relations. Psychol Bull 141(1):6-47

Arnett JJ (2012) Adolescence and emerging adulthood. Pearson College Division, Boston

Balmford A, Clegg L, Coulson T, Taylor J (2002) Why conservationists should heed Pokémon. Science 295(5564):2367-2367

Balmford A, Manica A, Airey L, Birkin L, Oliver A, Schleicher J (2004) Hollywood, climate change, and the public. Science 305(5691):1713

Barton J, Bragg R, Wood C, Pretty J (2016) Green exercise: linking nature, health and well-being. Earthscan Routledge, Oxford

Bratman GN, Hamilton JP, Daily GC (2012) The impacts of nature experience on human cognitive function and mental health. Ann N Y Acad Sci 1249 (1):118-136

Brewer C (2003) Computers in the classroom: how information technology can improve conservation education. Conserv Biol 17(3):657-660

Brodie JF (2016) Synergistic effects of climate change and agricultural land use on mammals. Front Ecol Environ 14(1):20-26

Butchart SHM, Walpole M, Collen B, van Strien A, Scharlemann JPW, Almond REA et al. (2010) Global biodiversity: indicators of recent declines. Science 328(5982):1164-1168

Clayton S, Litchfield C, Geller ES (2013) Psychological science, conservation, and environmental sustainability. Front Ecol Environ 11(7):377-382

Curtis DJ, Reid N, Reeve I (2014) Towards ecological sustainability: observations on the role of the arts. SAPIENS 7(1):P1-P15

Díaz S et al. (2019) Summary for policymakers of the global assessment report on biodiversity and ecosystem services of the Intergovernmental Science-Policy Platform on Biodiversity and Ecosystem Services, Bonn, Germany

Dickinson JL, Shirk J, Bonter D, Bonney R, Crain RL, Martin J, Phillips T, Purcell K (2012) The current state of citizen science as a tool for ecological research and public engagement. Front Ecol Environ 10(6):291-297

Dingwall R, Aldridge M (2016) Television wildlife programming as a source of popular scientific information: a case study of evolution. Public Under Sci 15 (2):131-152

Dirzo R, Young HS, Galetti M, Ceballos G, Isaac NJB, Collen B (2014) Defaunation in the Anthropocene. Science 345(6195):401-406

Dorward LJ, Mittermeier JC, Sandbrook C, Spooner F (2017) Pokémon Go: benefits, costs, and lessons for the conservation movement. Conserv Lett 10 (1):160-165

Echeverri A, Callahan MM, Chan KMA, Satterfield T, Zhao J (2017) Explicit not implicit preferences predict conservation intentions for endangered species and biomes. PLoS ONE 12(1):e0170973. https://doi.org/10.1371/journal. pone. 0170973

Fletcher R (2017) Gaming conservation: nature 2.0 confronts nature-deficit disorder. Geoforum 79:153-162

Frishkoff LO, Karp DS, M'Gonigle LK, Mendenhall CD, Zook J, Kremen C et al. (2014) Loss of avian phylogenetic diversity in neotropical agricultural systems. Science 345(6202):1343-1346

Garris R, Ahlers R, Driskell JE (2002) Games, motivation, and learning: a research and practice model. Simulat Gaming 33(4):441-467

Goodwin T (2016) Educating for ecological literacy. Am Biol Teach 78(4):287-291

Hausmann A, Toivonen T, Heikinheimo V, Tenkanen H, Slotow R, Di Minin E (2017) Social media reveal that charismatic species are not the main attractor of ecotourists to sub-Saharan protected areas. Sci Rep 7(1):763

Hull IV RB, Michael SE (1995) Nature-based recreation, mood change, and stress restoration. Leis Sci 17(1):1-14 
Jones N (2018). The deck stacked against women in science. Nature Blogs: a view from the bridge. http://blogs.nature.com/aviewfromthebridge/2018/03/08/ the-deck-women-in-science/ Accessed 8 Mar. 2018

Karp DS, Frishkoff LO, Echeverri A, Zook J, Juarez P, Chan KMA (2018) Agriculture erases climate-driven beta-diversity in Neotropical bird communities. Glob Chang Biol 24(1):338-349

Kollmuss A, Agyeman J (2010) Mind the gap: why do people act environmentally and what are the barriers to pro-environmental behavior? Environ Educ Res $8(3): 239-260$

Laurillard D (2013) Rethinking university teaching: a conversational framework for the effective use of learning technologies. Routledge, Oxford

Louv R (2008) Last child in the woods: saving our children from nature-deficit disorder. Algonquin Books, Chapel Hill

McBride BB, Brewer CA, Berkowitz AR, Borrie WT (2013) Environmental literacy, ecological literacy, ecoliteracy: what do we mean and how did we get here? Ecosphere 4(5):1-20

McKinley A (2008) Hope in a hopeless age: environmentalism's crisis. Environmentalist 28(3):319-326

Ng D (2015) Phylo: a crowdsourced biodiversity \& science trading card game. Presented at the Games Learning Society Proceedings, ETC Press, Pittsburgh, pp 403-409

Orr DW (1992) Ecological literacy: education and the transition to a postmodern world. SUNY Press, Albany

Papworth SK, Nghiem TPL, Chimalakonda D, Posa MRC, Wijedasa LS, Bickford D, Carrasco LR (2015) Quantifying the role of online news in linking conservation research to Facebook and Twitter. Conserv Biol 29(3):825-833

Paras B, and Bizzocchi J (2005) Game, motivation, and effective learning: an integrated model for educational game design. Presented at the 2nd International Conference on Digital Games Research Association DiGRA, Vancouver, Canada

Qualtrics LLC (2005) Qualtrics: online survey software and insight platform. Provo, Utah

Sandbrook C, Adams WM, Monteferri B (2014) Digital games and biodiversity conservation. Conserv Lett 8(2):118-124

Schuttler SG, Sorensen AE, Jordan RC, Cooper C, Shwartz A (2018) Bridging the nature gap: can citizen science reverse the extinction of experience? Front Ecol Environ 16(7):405-411

Silk MJ, Crowley SL, Woodhead AJ, Nuno A (2017) Considering connections between Hollywood and biodiversity conservation. Conserv Bio 32(3):597-606

Soga M, Gaston KJ (2016) Extinction of experience: the loss of human-nature interactions. Front Ecol Environ 14:94-101

Slovic P, Finucane ML, Peters E, MacGregor DG (2007) The affect heuristic. Eur J Oper Res 177(3):1333-1352

Slovic P, Finucane ML, Peters E, MacGregor DG (2004) Risk as analysis and risk as feelings: some thoughts about affect, reason, risk, and rationality. Risk Anal 24(2):311-322

Smith AM, Sutton SG (2008) The role of a flagship species in the formation of conservation intentions. Hum Dimens Wildl 13(2):127-140

Swanson TM (1994) The economics of extinction revisited and revised: a generalized framework for the analysis of the problems of endangered species and biodiversity losses. Oxf Econ Pap 46:800-821

Sweetser P, Johnson D, Ozdowska A, and Wyeth P (2012) GameFlow heuristics for designing and evaluating real-time strategy games. Presented at the The 8th Australasian Conference, New York, New York: ACM Press, pp 1-10
Turkay S, Adinolf S, Tirthali D (2012) Collectible card games as learning tools. Procedia Soc Behav Sci 46:3701-3705

Turner WR, Nakamura T, Dinetti M (2004) Global urbanization and the separation of humans from nature. Bioscience 54(6):585-590

Verma A, van der Wal R, Fischer A (2015) Microscope and spectacle: on the complexities of using new visual technologies to communicate about wildlife conservation. Ambio 44(S4):S648-S660

Watson D, Clark LA, Tellegen A (1988) Development and validation of brief measures of positive and negative affect: the PANAS scales. J Pers Soc Psychol 54(6):1063-1070

\section{Acknowledgements}

We thank those who generously agreed to participate in this study. We also thank Amit Chhina, Katie Edge, Claire Honda, Carlina Kim, Gabriel McKeown, Isabelle Simm, and members of the Zhao Lab for support on data collection. We also thank Kai Chan for his support with the conceptualization of this work. Additionally we thank Finn Simonsen for his support. This research was approved by the University of British Columbia (UBC) Behavioral Research Ethics Board (ethics certificate number H16-03088). AE was supported by a Global Graduate Leadership Fellowship from UBC and by a Killam Doctoral Scholarship. This study was funded and MMC was supported by a grant awarded to DN from the Michael Smith Lab from UBC. JZ was supported by the Canada Research Chair Program and Canada Foundation for Innovation. TS was supported by Social Sciences and Humanities Research Council (SSHRC) 435-2013-2017.

\section{Additional information}

The online version of this article (https://doi.org/10.1057/s41599-019-0287-9) contains supplementary material, which is available to authorized users.

Competing interests: The authors declare no competing interests.

Reprints and permission information is available online at http://www.nature.com/ reprints

Publisher's note: Springer Nature remains neutral with regard to jurisdictional claims in published maps and institutional affiliations.

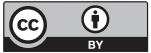

Open Access This article is licensed under a Creative Commons Attribution 4.0 International License, which permits use, sharing, adaptation, distribution and reproduction in any medium or format, as long as you give appropriate credit to the original author(s) and the source, provide a link to the Creative Commons license, and indicate if changes were made. The images or other third party material in this article are included in the article's Creative Commons license, unless indicated otherwise in a credit line to the material. If material is not included in the article's Creative Commons license and your intended use is not permitted by statutory regulation or exceeds the permitted use, you will need to obtain permission directly from the copyright holder. To view a copy of this license, visit http://creativecommons.org/ licenses/by/4.0/

(C) The Author(s) 2019 